\title{
CD44 Targeted Agent SPL-108
}

National Cancer Institute

\section{Source}

National Cancer Institute. CD44 Targeted Agent SPL-108. NCI Thesaurus. Code C142813.

A proprietary agent that targets the cancer stem cell (CSC) antigen CD44, with potential antineoplastic activity. Although the mechanism of action has not been elucidated, following subcutaneous administration, CD44 targ eted agent SPL-108 binds to CD44 and prevents the activation of various CD44-mediated signal transduction pathways, which may lead to reduced proliferation of CD44-expressing tumor stem cells. CD44, a transmembrane glycoprotein and hyaluronic acid receptor, is expressed in healthy tissue and overexpressed in numerous cancer cell types; it plays a key role in the proliferation, migration and survival of tumor cells. 